\title{
Solution-Grown Method of CdS Film by Ultrasonical Colloid Chemistry Deposition Technique
}

\author{
Hai-Ning Cui, ${ }^{1,2}$ Manuel F. Costa, ${ }^{1}$ V. Teixeira, ${ }^{1}$ and Jun Zhang ${ }^{3}$ \\ ${ }^{1}$ Physics Department, University of Minho, Campus de Gualtar, 4720-057 Braga, Portugal \\ ${ }^{2}$ College of Physics, Jilin University, 130023 Changchun, China \\ ${ }^{3}$ Department of Chemistry, University of Helsinki, P.O. Box 55, 00014 Helsinki, Finland
}

Received 24 January 2006; Accepted 20 March 2006

A technique called ultrasonical colloid chemistry deposition (UCCD) has been used to produce bar-shaped ultrafine particles (UFP) cadmium sulphide films. UV-visible spectra and electron micrographic characterization results are presented and discussed. The thin films were analyzed by means of grazing incidence X-ray diffraction (GIXD) and X-ray diffraction (XRD). Detailed results about the amorphous characterization of the films during room temperature growth and post annealing are given.

Copyright (c) 2006 Hai-Ning Cui et al. This is an open access article distributed under the Creative Commons Attribution License, which permits unrestricted use, distribution, and reproduction in any medium, provided the original work is properly cited.

\section{INTRODUCTION}

During the past decade a great deal of research has been done by different groups in an attempt to manufacture and characterize CdS ultrafine particles (UFP) films, because their structures have significant physical properties that are intermediate between those corresponding to molecules and to bulk material $[1,2]$. As we know this presents rather difficult problems, in both practical use and theoretical analysis, that is first, how to make macroscopic amount of stabilized and characterized UFP and relevant solid films; second, how to control the average size of the particles and obtain a very narrow distribution of sizes; third, how to control the shape of the particles and passivate the surface of the UFP film.

One of the possible ways to solve these problems simultaneously is to restrict the reaction volume in which the particles are created by some means. This has been done using various methods and templates such as colloid chemistry [3], electrochemistry [4], UFP accommodated by organic molecular [5], porous glasses [6], zeolites [7], synthetic clay [8], and core-shell type [2]. However, each of the above methods is not sufficient. In addition, the film of CdS is generally deposited by several techniques such as vacuum evaporation, sputtering, chemical vapor deposition, spray pyrolysis, and precipitable way from an aqueous solution. However, the solution-grown method for CdS has been given much attention $[9,10]$. Using this method, a very thin highly resistive layer can be deposited with good coverage and a low-cost for the manufacture of thin film solar cells. We have suggested that ultrasonation could be used as the restricted reaction volumes for the synthesis [11] of a compound semiconductor UFP film. Acoustic waves of the high frequency applied at sufficient rates to the solution can cause the cavitation that restricts the reaction volume and results in breaking up the large particles into smaller parts. Moreover, when certain conditions are met, the film formed presents a narrower size distribution. Here a novel technique called ultrasonical colloid chemistry deposition (UCCD) is proposed to produce cadmium sulphide (CdS) films. In the UCCD technique a cadmium complex (ammonia, triethanolamine) and an organic sulfidizing agent (thiourea or thioacetamide) provide very low concentrations of $\mathrm{Cd}^{++}$and $\mathrm{S}^{=}$in solution. When the product of the ion concentration exceeds the solubility product of CdS, a chemical reaction takes place precipitating a bar-shaped CdS UFP film when certain conditions such as $\mathrm{pH}$, temperatrue, ultrasonic are met.

\section{EXPERIMENTAL}

Our experimental setup is shown schematically in Figure 1. It consists of two main parts. The first is the reaction bath in which the temperature of the bath is monitored by a contact thermometer that forms a part of a feedback circuit controlling the heater to maintain a constant temperature. The second is the ultrasound source where the frequency and ultrasonic intensity can be controlled and maintained at a constant level. CdS particles films were deposited on a normal microscope slide by UCCD. The deposition bath was prepared by mixing $200 \mathrm{~mL}$ of $0.01 \mathrm{~mol} / \mathrm{L} \mathrm{CdCl}$, $0.038 \mathrm{~mol} / \mathrm{L} \mathrm{NH}{ }_{4} \mathrm{Cl}$, and $0.78 \mathrm{~mol} / \mathrm{L} \mathrm{NH}_{4} \mathrm{OH}$, and $200 \mathrm{~mL}$ 


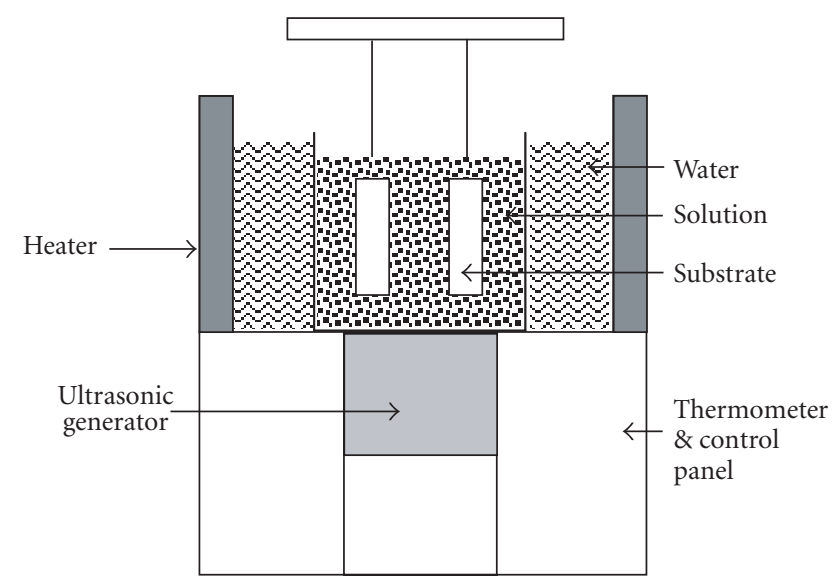

FIGURE 1: Experimental arrangement of ultrasonical colloid chemistry deposition method (UCCD).

of $0.16 \mathrm{~mol} / \mathrm{L}$ Thiourea $\left[\mathrm{S}=\mathrm{C}\left(\mathrm{NH}_{2}\right)_{2}\right], 0.038 \mathrm{~mol} / \mathrm{L} \mathrm{NH}{ }_{4} \mathrm{Cl}$, and $0.78 \mathrm{~mol} / \mathrm{L} \mathrm{NH}_{4} \mathrm{OH}$ in a beaker. The beaker was placed in a water bath with an ultrasonical device. The cleaned substrate [12] was then immersed in the deposition bath, and left for the required time with the temperature of the solution being kept at $60-90^{\circ} \mathrm{C}$. The chosen frequency was of $42000 \mathrm{~Hz}$. The ultrasonic power was of more than 50 Watts. The $\mathrm{pH}$ value of the solution combined was of approximately 11 . The optical transmission spectra of the UFP films were measured at room temperature with a Shimadzu UV-3000 spectrophotometer. Their microstructures were investigated by scanning electron micrography (SEM, Japan Hitachi model s-2400 \& Japan JEOL-JXA-840).

\section{DISCUSSION AND RESULTS}

\section{UV-vis spectra}

Due to the high pressure and high temperature in the cavitation of the liquid, the CdS UFP films obtained were transparent, highly adherent, spectrally reflective, and had a yellow appearance with a light blue tinge. Since the data in terms of transmission is more informative [2], transmission spectra (Figure 2) were measured in order to get a visualization of the absorption onset. It is found that the onset of the spectra curve using UCCD method is located at $450 \mathrm{~nm}$ and it is shifted towards shorter wavelengths from the bulk value of $512 \mathrm{~nm}$ by $60 \mathrm{~nm}$. The slope of the edge of the transmission curve is steep in accordance with a narrow distribution of particle sizes. The absorption peak (transmission onset) which is present at $415 \mathrm{~nm}$ is due to a $1 \mathrm{~s}$-1s quantum particle transition as suggested by Rajeshwar and Brus $[4,13]$.

\section{Formation of CdS UFP films}

Another purpose of using ultrasonic during the deposition is to facilitate the transport of $\mathrm{Cd}^{++}$and $\mathrm{S}^{=}$to the substrate surface. When the ions move towards the substrate, first there would be an actual inception of submicroscopic

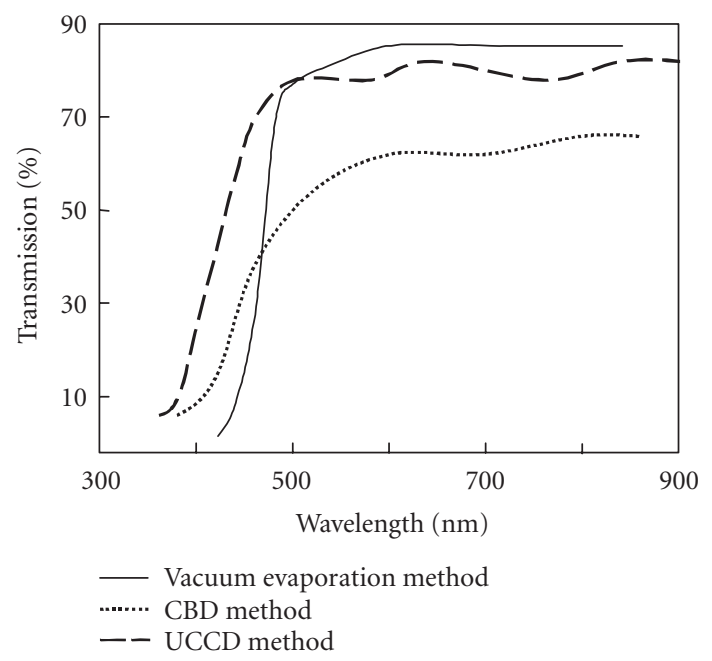

FIGURE 2: The transmission of a CdS film, using a vacuum evaporation method (solid line); using a chemical bath deposition (CBD) method (dotted line); and ultrasonical colloid chemistry deposition (UCCD) method (dashed line).

nuclei, growth of the submicroscopic nuclei, and an ionby-ion reaction which occurs at the solid-liquid interface forming a compact film on the substrate. It is generally assumed that solutions in a supersaturated state constitute microheterogeneous systems in the form of a solution of suspended crystal subnuclei. Second, in the traditional solutiongrown method, where the deposition time is usually a bit higher it results in a cluster-by-cluster growth in the solution and on substrate, whereby clusters coalesce through an attractive force (probably van der Waals [9]). The growth of these nuclei to a certain equilibrium size by diffusion and flowage is scarcely probable, and is possible by their convergence and subsequent coalescence into loosely clustered aggregates which become larger particles or disperse phase conglomerates. The formation of a large number of clusters in the two-phase solidification zone inhibits the motion of nuclei and the liquid phase because the canals between the cluster and dendrites can diminish to capillary dimensions. The CdS solidifies before the liquid phase enters the capillaries resulting in the formation of pores and shrinkage cavities. In UCCD, ultrasonic excitation could break the second process. It opposes the growth of the pores of the cluster. The formation of pores is inhibited. If we take an account of the fact that dendrite formations are present at the instant of crystallization, we realize that they can be broken up and cast into the solution by shaking, vibration, or ultrasonic irradiation. The breakdown of the dendrite branches by vibration tends to eliminate the pores and shrinkage cavities in the solidifying CdS. Polycrystal particles with a diameter on the order of $10^{-7} \mathrm{~m}$ suspended in the film, which are present in the majority of CdS, become a CdS film which can be partially cut or ground by the vibrating medium, thus allowing the production of a high-quality film.

In general the particles are not always of spherical shape. They can have different shapes. Their adhesive force can be 


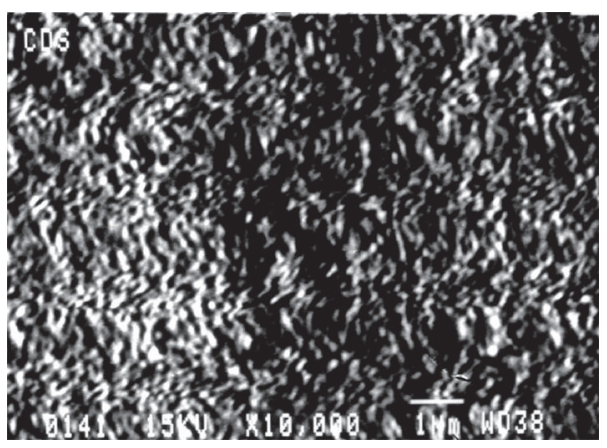

FIgURE 3: SEM image of a CdS film deposited using the UCCD method at $15 \mathrm{kV}$. The scale is $1 \mathrm{~mm}$.

van der Waals, electrical double layer, capillary and electrostatic. In theory these forces are directly proportional in magnitude to the size of the particle. Sinterization as well as film deposition at high temperatures is a coalescence mechanism on neck (bar) forms involving islands in contact $[14,15]$. The driving force for neck growth is simply the natural tendency to reduce the total surface energy (or area) of the system. Since atoms on the convex island surfaces have a greater activity than atoms situated in the concave neck, an effective concentration gradient between these regions develops. This results in the observed mass transport into the neck. Surface energy and diffusion-controlled mass-transport mechanisms influence liquid-like coalescence phenomena involving islands in contact. Other driving forces such as electric field [14] and flowage field are probably also active. In the deposition process of the CdS films, the driving forces come probably from the ultrasonic field. The final shape of the particles as viewed by SEM (Figure 3) is bar (or neck) and not quasispherical after prolonging the time of deposition further. This also happens because the oriented ultrasonic progress (field) and flowage field limit the expansion or coalescence of neck island along the diameter direction of neck mechanism promoted by the surface energy in high temperature heat fields.

For the traditional (nonultrasonic) method, when the deposition time continues a bit longer (several minutes) from the beginning, the size of the colloids increases with the reaction time and reaches higher sizes. The process is called cluster-by-cluster growth of colloids. In Figure 3, it is found that the films are formed by a condensed layer of good quality and have the texture surface which can be obtained by chemical etching $[16,17]$ in UCCD. The deposition time was more than $50 \mathrm{~min}$. It was observed that on the microscopic scale the film was even. Large particles were broken into uniform particles or did not form at all under the ultrasonic wave field. The film is clearly made up of connected small bar-shaped particles with a typical bar diameter of $100 \mathrm{~nm}$. It is easy to impose an upper limit of less than $300 \mathrm{~nm}$ in length of the bar-shaped particles.

In an ultrasonic field $(42 \mathrm{kHz})$ the bar-shaped grain of $\mathrm{CdS}$ is refined in the volume range $0.1 \times 3.0$ micrometer.

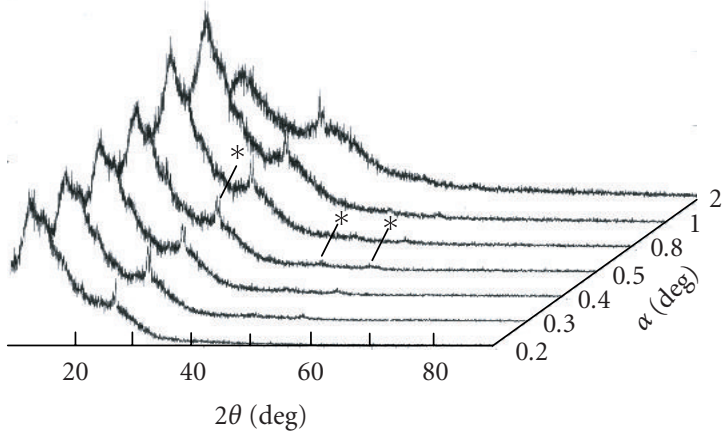

FIGURE 4: Grazing incidence X-ray diffraction (GIXRD) at different incidence angles. CdS as deposited ( $*-\mathrm{CdS})$.

The process just described actually represents the aging of a solution. In addition, the behavior of the processes in an ultrasound field is fully due to the ability of the ultrasound to produce microturbulence at the bounding surfaces and to accelerate the mass transfer of matter from one phase to another. Moreover, acoustic cavitation generated by the sound field play a vital part in the peptizing method deposition action of ultrasound.

\section{GIXRD study of CdS}

In order to study the internal layer of CdS, we show the grazing incidence X-ray diffraction (GIXRD) results obtained on three samples in Figure 4. They are CdS films $(210 \mathrm{~nm})$ asdeposited on glass. GIXRD spectra for the unheated CdS film on glass, at different incidence angles $\left(\alpha=0.20^{\circ}-2.00^{\circ}\right)$ are given in Figure 4. The diffraction lines reveal the existence of CdS from the surface $\left(\alpha=0.20^{\circ}\right)$ to the bottom $\left(\alpha=2.00^{\circ}\right)$ of the film. The X-ray penetration depth is calibrated from $25 \mathrm{~nm}$ to $480 \mathrm{~nm}$, when the incidence angles varied from $0.20^{\circ}$ to $5.00^{\circ}$. The CdS peaks that appear at incidence angles $\alpha=2.00^{\circ}$ show that the thickness of the CdS films (the $\mathrm{X}$-ray penetration depth) is of approximately $210 \mathrm{~nm}$. This is in agreement with the thickness measured by ellipsometry.

\section{$X R D$ of the films}

Figure 5 shows the XRD of CdS films deposited at different annealing temperatures. Polycrystalline hexagonal and cubic CdS are present showing several strong X-ray diffraction peaks. The diffraction spectra were obtained by using $2 \theta$ scanning in the range $20^{\circ}-55^{\circ}$. It can be seen that the as-deposited film has a mixed cubic and hexagonal forms of CdS. The peak at $2 \theta=24.8^{\circ}$ corresponds to the hexagonal (100) plane, the peak at $2 \theta=26.5^{\circ}$ corresponds to the mixture of hexagonal (002) and cubic (110) planes. The peak at $2 \theta=43.9^{\circ}$ comes from the hexagonal (110) and cubic (220) planes and the peak at $2 \theta=52.8^{\circ}$ corresponds to the hexagonal (112) and cubic (311) planes. When the annealing temperature was increased to $400^{\circ} \mathrm{C}$, the peaks at $2 \theta=28.2^{\circ}, 50.8^{\circ}$, and $52.8^{\circ}$, which come from the hexagonal 


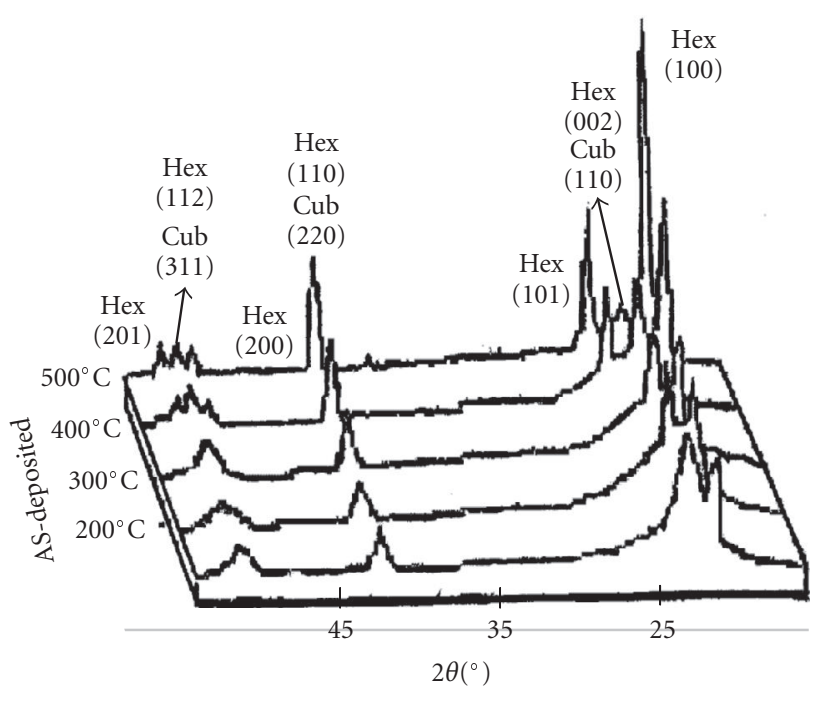

FIgure 5: The X-ray diffraction (XRD) of the CdS films at different annealing temperatures. Intensity is in arbitrary units.

(101), (200), and (201) planes, appeared. At the same time, the height of the peak at $2 \theta=26.5^{\circ}$ decreased and the peak at $43.9^{\circ}$ increased. This indicates that the increase of the hexagonal structure content starts at $400^{\circ} \mathrm{C}$ which is $100^{\circ} \mathrm{C}$ lower than Hiroshi Uda’s results [18].

\section{CONCLUSION}

A technique called ultrasonical colloid chemistry deposition has been proposed to produce bar-shaped UFP film of cadmium sulphide. The main point of the technique is that by feeding the ultrasonic generator with a known concentration of ions, we can define the size of chemical reaction volume in solution, break up the large particles, and hence define the size and bar-shaped form of the final solid particles also. This method is used instead of a chemical etching step and directly got the texture surface of the semiconductor film. In this sense the method could be applied to other kinds of films and has great potential for the production of UFP semiconductor materials.

Dipped CdS films are known to be amorphous. XRD have been used to analyze the material structure and confirm that the prepared films are CdS. CdS films obtained using UCCD have a wider transmission range, a higher transmittance, and better uniformity than those obtained using the CBD method.

\section{REFERENCES}

[1] V. I. Boev, C. J. R. Silva, and M. J. M. Gomes, "Synthesis and characterization of a sol-gel derived ureasilicate hybrid organic-inorganic matrix containing CdS colloidal particles," Journal of Sol-Gel Science and Technology, vol. 31, no. 1-3, pp. 131-135, 2004.

[2] Y. C. Tian, T. Newton, N. A. Kotov, D. M. Guldi, and J. H. Fendler, "Coupled composite CdS-CdSe and core-shell types of (CdS)CdSe and (CdSe)CdS nanoparticles," Journal of Physical Chemistry, vol. 100, no. 21, pp. 8927-8939, 1996.

[3] J. H. Fendler and F. C. Meldrum, "The colloid chemical approach to nanostructured materials," Advanced Materials, vol. 7, no. 7, pp. 607-632, 1995.

[4] K. Rajeshwar, "Electrosynthesized thin films of group II-VI compound semiconductors, alloys and superstructures," Advanced Materials, vol. 4, no. 1, pp. 23-29, 1992.

[5] M. Wu, W. Z. Gu, W. Z. Li, X. W. Zhu, F. D. Wang, and S. T. Zhao, "Preparation and characterization of ultrafine zinc sulfide particles of quantum confinement," Chemical Physics Letters, vol. 224, no. 5-6, pp. 557-562, 1994.

[6] J. Kuczynski and J. K. Thomas, "Photophysical properties of cadmium sulfide deposited in porous Vycor glass," Journal of Physical Chemistry, vol. 89, no. 13, pp. 2720-2722, 1985.

[7] S. L. Suib, "Zeolitic and layered materials," Chemical Reviews, vol. 93, no. 2, pp. 803-826, 1993.

[8] R. D. Stramel, T. Nakamura, and J. K. Thomas, "Cadmium sulfide on synthetic clay,” Chemical Physics Letters, vol. 130, no. 5, pp. 423-425, 1986.

[9] H.-N. Cui and S.-Q. Xi, "The fabrication of dipped CdS and sputtered ITO thin films for photovoltaic solar cells," Thin Solid Films, vol. 288, no. 1-2, pp. 325-329, 1996.

[10] J. M. Dona and J. Herero, "Chemical codeposited. CdS-ZnS film characterization," in Proceedings of 12th European Photovoltaic Solar Energy Conference, Amsterdam, The Netherlands, April 1994, P. 3B. 3.

[11] H.-N. Cui, R. Wang, H. J. Zhang, L. Y. Wang, and S.-Q. Xi, China Patent, The application and public number: $96123704 x$, December 1996.

[12] H.-N. Cui, W. Wang, E. Zhou, and X. Zhao, "Preparation and characterization of Langmuir-Blodgett films of porphyrins without long alkyl chains," Thin Solid Films, vol. 214, no. 2, pp. 238-242, 1992.

[13] L. E. Brus, "Zero-dimensional "excitons" in semiconductor clusters," IEEE Journal of Quantum Electronics, vol. 22, no. 9, pp. 1909-1914, 1986.

[14] R. M. German, Powder Metallurgy Science, Metal Powder Industries Federation, Princeton, NJ, USA, 1984.

[15] D. W. Pashley and M. J. Stowell, "Nucleation and growth of thin films as observed in the electron microscope," Journal of Vacuum Science and Technology, vol. 3, no. 3, pp. 156-166, 1966.

[16] R. A. Arndt, J. F. Allison, A. Meulenberg Jr., and J. G. Haynos, "Optical properties of the COMSAT non-reflective cell," in Proceedings of 11th IEEE Photovoltaic Specialists Conference, pp. 40-43, Scottsdale, Ariz, USA, May 1975.

[17] J. X. Wang, Y. R. Sun, and T. B. Li, "Some improvements in thin film $\mathrm{CdS} / \mathrm{Cu}_{2} \mathrm{~S}$ solar cells," Acta Energiae Solaris Sinica, vol. 3, no. 1, p. 37, 1982.

[18] Hirishi Uda, Seiji Ikegami, and Hajimu Sonomura, "Properties of CdS/CdTe solar cells with Cu2Te-Au contacts," Japanese Journal of Applied Physics, vol. 36, pp. 5549-5550, 1997. 


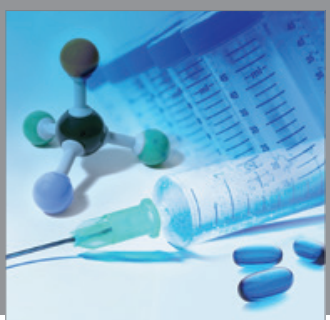

International Journal of

Medicinal Chemistry

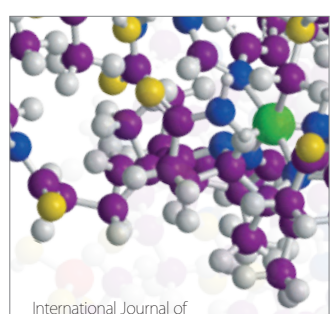

Carbohydrate Chemistry

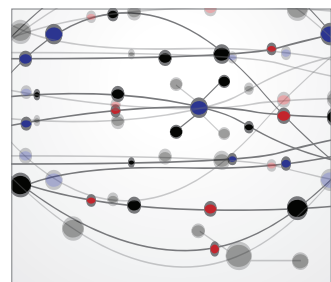

The Scientific World Journal
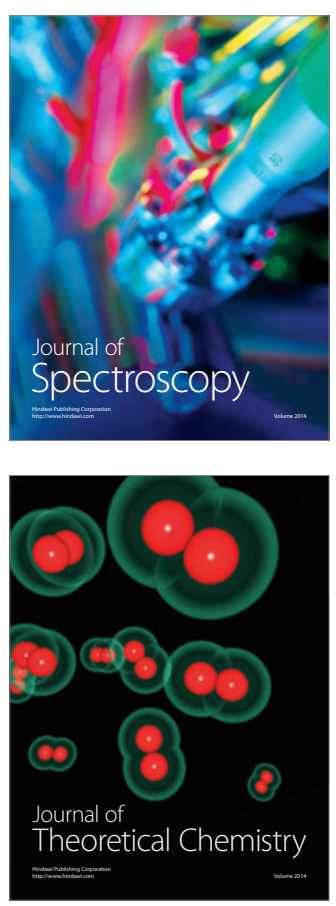
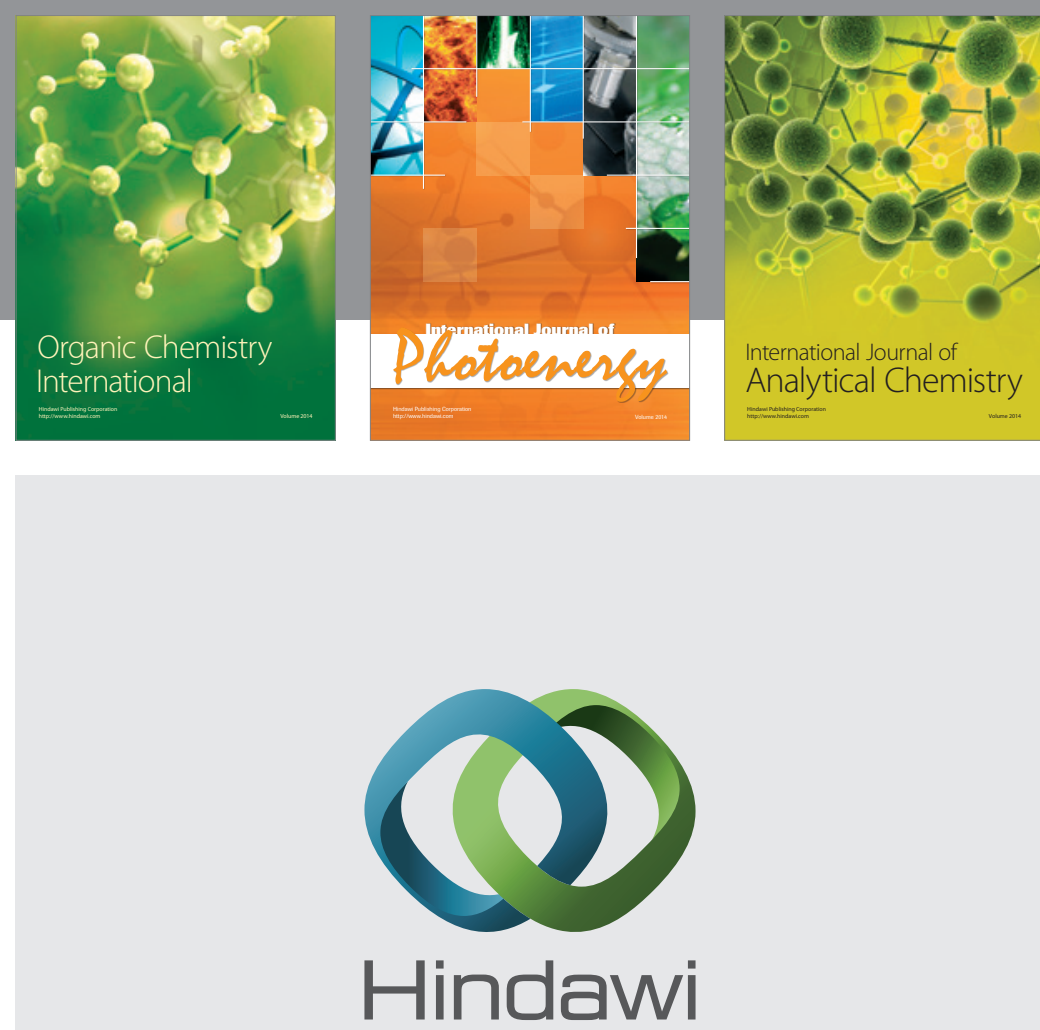

Submit your manuscripts at

http://www.hindawi.com
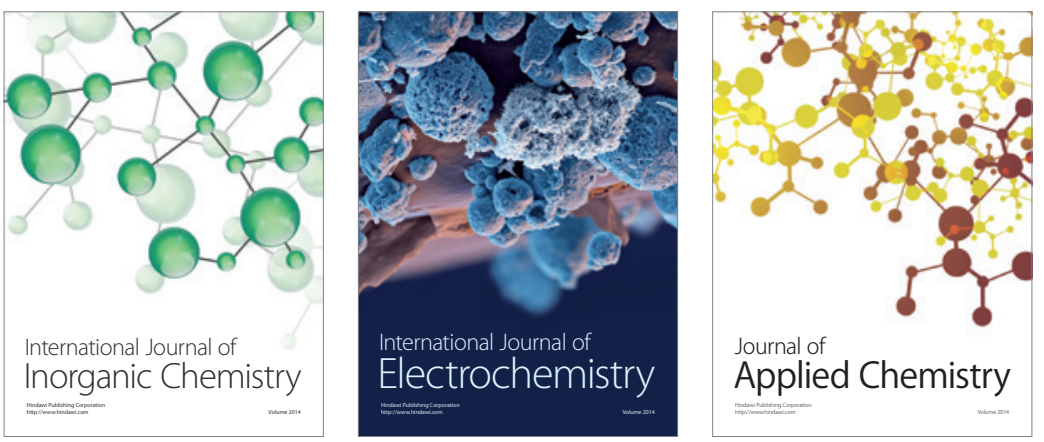

Journal of

Applied Chemistry
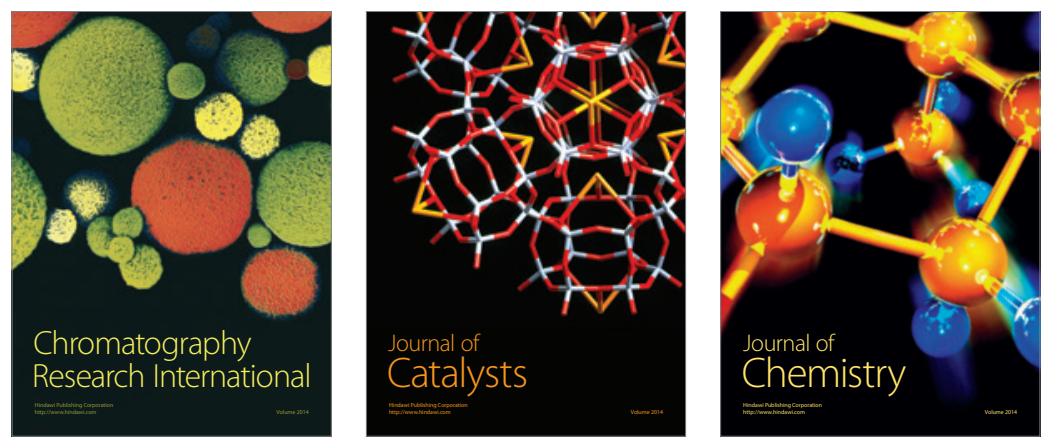
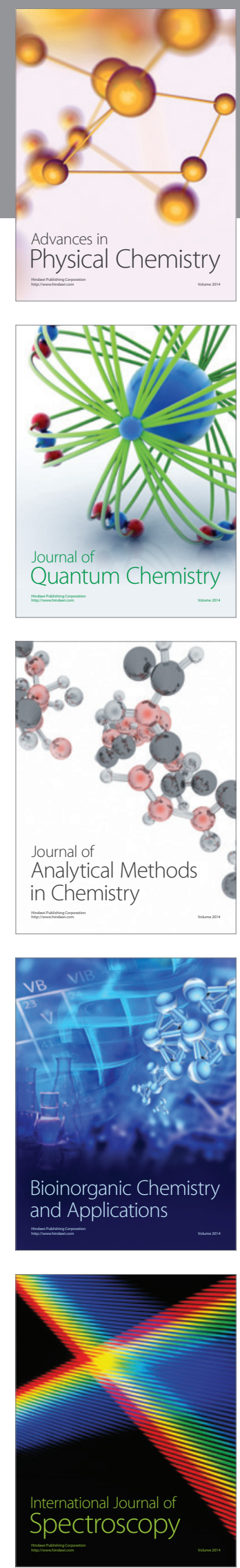